\title{
A Comprehensive Subcellular Proteomic Survey of Salmonella Grown under Phagosome-Mimicking versus Standard Laboratory Conditions
}

\author{
Roslyn N. Brown, ${ }^{1}$ James A. Sanford, ${ }^{2}$ Jea H. Park, ${ }^{1}$ Brooke L. Deatherage, \\ Boyd L. Champion, ${ }^{1}$ Richard D. Smith, ${ }^{1}$ Fred Heffron, ${ }^{3}$ and Joshua N. Adkins ${ }^{1}$ \\ ${ }^{1}$ Biological Sciences Division, Pacific Northwest National Laboratory, 902 Battelle Boulevard, Richland, WA 99352, USA \\ ${ }^{2}$ Biomedical Sciences Graduate Program, University of California San Diego, 9500 Gilman Dive, La Jolla, CA 92063, USA \\ ${ }^{3}$ Department of Molecular Microbiology and Immunology, Oregon Health and Science University, 3181 SW Sam Jackson Park Road, \\ Portland, OR 97239, USA
}

Correspondence should be addressed to Joshua N. Adkins, joshua.adkins@pnnl.gov

Received 16 March 2012; Accepted 6 June 2012

Academic Editor: Gary B. Smejkal

Copyright (c) 2012 Roslyn N. Brown et al. This is an open access article distributed under the Creative Commons Attribution License, which permits unrestricted use, distribution, and reproduction in any medium, provided the original work is properly cited.

Towards developing a systems-level pathobiological understanding of Salmonella enterica, we performed a subcellular proteomic analysis of this pathogen grown under standard laboratory and phagosome-mimicking conditions in vitro. Analysis of proteins from cytoplasmic, inner membrane, periplasmic, and outer membrane fractions yielded coverage of $25 \%$ of the theoretical proteome. Confident subcellular location could be assigned to over 1000 proteins, with good agreement between experimentally observed location and predicted/known protein properties. Comparison of protein location under the different environmental conditions provided insight into dynamic protein localization and possible moonlighting (multiple function) activities. Notable examples of dynamic localization were the response regulators of two-component regulatory systems (e.g., ArcB and PhoQ). The DNA-binding protein Dps that is generally regarded as cytoplasmic was significantly enriched in the outer membrane for all growth conditions examined, suggestive of moonlighting activities. These observations imply the existence of unknown transport mechanisms and novel functions for a subset of Salmonella proteins. Overall, this work provides a catalog of experimentally verified subcellular protein locations for Salmonella and a framework for further investigations using computational modeling.

\section{Introduction}

The pursuit of a systems-level understanding of bacterial physiology requires not only knowledge about the identity, function, and relative abundance of proteins, but also insight into the subcellular localization of these proteins. Subcellular protein localization is linked to protein function, potential protein-protein interactions, and to interactions between a cell and its exterior environment. The observation of proteins in unexpected cellular compartments gives clues about the presence of possible alternate functions. Hence, there is a growing appreciation for the presence of bacterial "moonlighting proteins," that is, those proteins that have a secondary function depending on subcellular location
[1-3]. Experimentally verified localization also provides a foundation for describing proteins that are "hypothetical," uncharacterized, or that contain domains of unknown function. Furthermore, with the increasing use of systems biology approaches, including genome-scale models of metabolism [4] and regulation to study microbial functions, experimentally founded protein localization on a global scale is necessary to produce more accurate model constraints.

Subcellular proteomics has emerged as a powerful tool for large-scale profiling of protein subcellular location [5-9]. Unlike traditional Western blot or high-resolution microscopy methods that rely on the use of antibodies or molecular tags to identify individual proteins, proteomic methods enable high-throughput, unbiased, and large-scale 
identification of the protein complement of subcellular fractions $[5,6,10]$. Moreover, interrogation of the subcellular proteome under different growth or environmental conditions allows for the investigation of changes in protein abundance and possibly protein location.

Subcellular proteomic analysis of bacterial pathogens holds promise for identifying novel virulence determinants and potential therapeutic targets [11-13]. For Gram-negative pathogens such as Salmonella enterica, each of the four main protein-containing compartments-the outer and inner membranes, periplasm, and cytoplasm - is a potential source of virulence determinants. Outer membrane/cell surface proteins mediate adhesion, cell-cell communication, immune evasion, sequestration, transport (including antibiotic efflux), and secretion, whereas inner membrane proteins accomplish transport and assembly of complex structures, such as flagella and secretion apparati. Periplasmic proteins sense and respond to the host environment, and cytoplasmic proteins include secretion substrates, chaperones, and housekeeping proteins important in maintaining the pathogenic lifestyle. Comprehensive characterization of these subcellular fractions can provide insight into the potential for virulencerelated interactions with the host as well as fundamental information on the subcellular architecture of this organism.

Our present goals were twofold: (1) to survey the localization of proteins in Salmonella cells as a reference of protein localization in this bacterium and (2) to observe changes in protein abundance or location upon growth under phagosome-mimicking conditions relative to standard laboratory conditions to generate new biological insights, as well as improved data for computational modeling. Towards this end, cytoplasmic (CYT), inner membrane (IM), periplasmic (PERI), and outer membrane (OM) fractions were analyzed using liquid chromatography-tandem mass spectrometry (LC-MS/MS). We did not analyze the secretome as we recently completed an extensive analysis of the proteins secreted by Salmonella under phagosomemimicking conditions [14]. In the present study, over 25\% of the theoretical Salmonella proteome was represented, and confident assignment of subcellular locations was achieved for most proteins. In addition, we assigned subcellular-level localization to the response of the bacteria to growth under conditions that mimic the host macrophage intracellular environment. This study represents the most comprehensive global survey of subcellular localization in Salmonella to date and affords a resource to others interested in protein location, improving location predictions and systems computational models.

\section{Methods}

2.1. Rationale for Media and Strains Used in This Study. Growth to mid-logarithmic phase in Luria-Bertani broth represents a standard laboratory growth condition in this study and is noninducing for Salmonella pathogenicity island 2 (SPI-2) gene expression [15]. Growth of Salmonella in defined, acidic media with low concentrations of phosphate and magnesium induces expression of SPI- 2 genes that are required for intracellular survival and replication [15-19]. mLPM has been shown to induce expression and secretion of SPI2-related virulence factors [14] and was used in this study to mimic the environment of a macrophage phagosome.

We previously identified flagellin (especially FliC) as one of the most abundant proteins secreted by Salmonella into culture media [14] and also in cell envelope fractions (Supplemental Table 1, supplementary material available online at doi: no\# 10.1155/2012/123076). Salmonella flagellins are downregulated during the intracellular stage of infection, and SPI-2-expressing bacteria are not motile [20]. Since flagella are not relevant to the stage of infection we intended to mimic, we deleted flagellin genes $f l i C$ and $f l j B$ from wildtype Salmonella enterica serovar Typhimurium ( $S$. Typhimurium) ATCC 14028 in an attempt to achieve better sensitivity by depleting these abundant proteins.

2.2. Bacterial Strains, Media, and Chemicals. Bacteria were maintained in LB broth (Difco, Franklin Lakes, NJ, USA) or on LB plates. Unless otherwise noted, components of mLPM [14] and other chemicals were purchased from Sigma (St. Louis, MO, USA). Protein concentrations were determined by bicinchoninic acid (BCA) assay (Pierce, Rockford, IL, USA) using bovine serum albumin as standards. Trypsin used for protein digestions was purchased from Promega (Madison, WI, USA).

2.3. Deletion of Flagellin Genes. In an attempt to achieve better sensitivity by depleting a nonessential abundant protein (Supplemental Table 1), a double-flagellin mutant $(\Delta f l i C \Delta f l j B)$ was created using $\lambda$ Red recombination [21]. fliC was deleted using oligos FliC P1: AGCCCAATAACATCAAGTTGTAATTGATAAGGAAAAGATCGTGTAGGCTGGAGCTGCTTC and FliC P2: CCTTGATTGTGTACCACGTGTCGGTGAATCAATCGCCGGACATATGAATATCCTCCTTAG.

For deleting $f l j B$, oligos FljB P1: GATTTTCTCCTTTACATCAGATAAGGAAGAATTTTAGTCGGTGTAGGCTGGAGCTGCTTC and FljB P2: CTCGCCCGTAGGAAATATCATTTACAGCCATACATTCCATCATATGAATATCCTCCTTAG were used. Underlined portions of the above oligos represent pKD4 sequences. Insertion of the kanamycin resistance cassette was confirmed using oligos FliC test1: AATGATGAAATTGAAGCCAT and K1: CAGTCATAGCCGAATAGCCT for $f l i C$ and using FljB test1: AACGCCACCAGGTTTTTCAC and $\mathrm{K} 1$ for $f l j B$. The kanamycin resistance gene was removed using pCP20 as previously described [21]. The flagellin mutant was tested for lack of motility, compared to the wildtype, using $0.4 \%$ agar plates.

2.4. Subcellular Fractionation. Overnight starter cultures of WT and the $\Delta f l i C \Delta f l j B$ mutant were grown in LB broth at $37^{\circ} \mathrm{C}$ with shaking at $200 \mathrm{rpm}$. The cultures were diluted $1: 100$ into LB and grown to mid-log phase (OD600 0.6) for the "LB-log" condition or diluted 1:10 into mLPM and grown for 4 or $20 \mathrm{~h}$ for "LPM4" and "LPM20," respectively. 
The cell fractionation protocol was adapted from that described by Brown et al. [9]. Unless otherwise noted, centrifugation steps were performed at $4^{\circ} \mathrm{C}$. Cells were collected via centrifugation $(10,000 \times \mathrm{g}, 10 \mathrm{~min})$ and washed with $10 \mathrm{~mL}$ of $50 \mathrm{mM}$ Tris-HCl (pH 8.0). PERI fractions were generated by suspending cell pellets in $10 \mathrm{~mL}$ spheroplasting buffer ( $50 \mathrm{mM}$ Tris- $\mathrm{HCl}, \mathrm{pH} 8,250 \mathrm{mM}$ sucrose, $2.5 \mathrm{mM}$ EDTA) and incubating at room temperature for $5 \mathrm{~min}$, after which they were centrifuged at $11,500 \times \mathrm{g}$ for $10 \mathrm{~min}$. Pellets were then suspended in $1.3 \mathrm{~mL}$ cold $5 \mathrm{mM} \mathrm{MgSO}_{4}$ and kept on ice for $10 \mathrm{~min}$ with occasional mixing. After centrifugation $(11,500 \times \mathrm{g}, 10 \mathrm{~min})$, the supernatant was retained as the soluble PERI fraction, while the pelleted spheroplasts were suspended in $1.0 \mathrm{~mL} 20 \mathrm{mM}$ $\mathrm{NaH}_{2} \mathrm{PO}_{4}$.

Half of the spheroplasts from each condition were then used to perform fractionation into CYT, IM, and $\mathrm{OM}$ fractions. The volumes were adjusted to $3.0 \mathrm{~mL}$ in $20 \mathrm{mM} \mathrm{NaH}_{2} \mathrm{PO}_{4}$ and lysed by passing three times through a prechilled French Press (8,000 PSI). Cell lysate suspensions were adjusted to $10 \mathrm{~mL}$ using $20 \mathrm{mM} \mathrm{NaH}{ }_{2} \mathrm{PO}_{4}$ and centrifuged at $5,000 \times \mathrm{g}$ for $30 \mathrm{~min}$ to pellet unbroken cells. Supernatants were then centrifuged at $45,000 \times \mathrm{g}$ for 60 min to separate the soluble CYT fraction from the crude membrane pellet. The CYT fractions were centrifuged again to remove residual membrane contaminants. After tubes containing membrane pellets were inverted to dry, the pellets were suspended in $10 \mathrm{~mL} 20 \mathrm{mM} \mathrm{NaH} \mathrm{PO}_{4}$ containing $0.5 \%$ Sarkosyl and shaken at $200 \mathrm{rpm}$ for $30 \mathrm{~min}$ at room temperature. This mixture was then centrifuged at $45,000 \times \mathrm{g}$ for $60 \mathrm{~min}$ to pellet the $\mathrm{OM}$ fraction, and the supernatant containing the IM fraction was removed. OM fractions were washed once by suspending in $5 \mathrm{~mL} \mathrm{NaH} \mathrm{PO}_{4}$ and repeating the centrifugation.

2.5. Tryptic Digests. Tryptic digests of the soluble CYT and PERI fractions were prepared as follows. To $75 \mu \mathrm{g}$ of protein from each sample, urea and DTT were added to final concentrations of $7 \mathrm{M}$ and $5 \mathrm{mM}$, respectively, followed by incubation at $60^{\circ} \mathrm{C}$ for $30 \mathrm{~min}$. Samples were then diluted 7 -fold with $100 \mathrm{mM} \mathrm{NH}_{4} \mathrm{HCO}_{3}$, and $\mathrm{CaCl}_{2}$ was added to a final concentration of $1 \mathrm{mM}$. Trypsin was then added in a $1: 50$ trypsin: protein ratio, and digestions were performed at $37^{\circ} \mathrm{C}$ with shaking at $600 \mathrm{rpm}$ for 3 hours. Following digestion, samples were cleaned using $1 \mathrm{~mL}, 50 \mathrm{mg}$ Discovery DSC-18 solid phase extraction (SPE) columns (Supelco, St. Louis, MO, USA). Briefly, each column was conditioned with methanol and then rinsed with $0.1 \%$ TFA in water. Digested samples were run through the columns under vacuum and rinsed with 95:5 $\mathrm{H}_{2} \mathrm{O}$ : ACN with 0.1\% TFA. Excess liquid was removed from the columns, and peptides were eluted using 80:20 ACN: $\mathrm{H}_{2} \mathrm{O}$ containing $0.1 \%$ TFA. Peptides were collected and concentrated using a SpeedVac (ThermoSavant) to a final volume of $50-100 \mu \mathrm{L}$, after which final peptide concentrations were determined by BCA protein assay.

Tryptic digests of the insoluble IM and OM fractions were prepared as follows. To $75 \mu \mathrm{g}$ of protein from each sample, urea, DTT, and CHAPS were added to final concentrations of $7 \mathrm{M}, 10 \mathrm{mM}$, and $1 \%$, respectively, followed by incubation at $60^{\circ} \mathrm{C}$ for $30 \mathrm{~min}$. Samples were then diluted 7-fold with $100 \mathrm{mM} \mathrm{NH} \mathrm{HCO}_{3}$, and $\mathrm{CaCl}_{2}$ was added to a final concentration of $1 \mathrm{mM}$. Digestion was performed as described for the soluble fractions. Digested samples were then cleaned using $1 \mathrm{~mL}, 50 \mathrm{mg}$ Discovery SCX strong cation exchange SPE columns (Supelco, St. Louis, MO, USA). Briefly, columns were conditioned with methanol and then rinsed in varying sequences and amounts of $10 \mathrm{mM}$ ammonium formate in $25 \% \mathrm{ACN}$ (pH 3.0), $500 \mathrm{mM}$ ammonium formate in $25 \% \mathrm{ACN}$ ( $\mathrm{pH} 6.8$ ), and nanopure water. Peptide samples were acidified to $\mathrm{pH}<4$ with formic acid, centrifuged at $10,000 \times \mathrm{g}$ for $5 \mathrm{~min}$, applied to the columns, and washed with $10 \mathrm{mM}$ ammonium formate in 25\% ACN (pH 3.0). Peptides were eluted using 80:15:5 $\mathrm{MeOH}: \mathrm{H}_{2} \mathrm{O}: \mathrm{NH}_{4} \mathrm{OH}$ and concentrated to a final volume of $50-100 \mu \mathrm{L}$ using a SpeedVac. Final peptide concentrations were calculated by BCA protein assay.

2.6. SDS-PAGE. For visualization of the protein fractions, $5 \mu \mathrm{g}$ of each protein sample was suspended in NuPAGE LDS sample buffer (Invitrogen, Carlsbad, CA, USA), heated at $70^{\circ} \mathrm{C}$ for $10 \mathrm{~min}$, and resolved on NuPAGE Novex $4-12 \%$ BisTris gradient gels (Invitrogen). Gels were run at a constant voltage of $200 \mathrm{~V}$ for $35 \mathrm{~min}$ and subsequently stained with GelCode Blue stain (Pierce) to observe protein profiles.

2.7. Capillary LC-MS/MS Analysis. The high-performance liquid chromatography (HPLC) system and method used for nanocapillary liquid chromatography have been described in detail elsewhere [19, 22]. Analysis was performed using an LTQ-Orbitrap mass spectrometer (Thermo Fisher Scientific, San Jose, CA, USA) with electrospray ionization. The HPLC column was coupled to the mass spectrometer using an inhouse manufactured interface. The heated capillary temperature and spray voltage were $200^{\circ} \mathrm{C}$ and $2.2 \mathrm{kV}$, respectively. Data acquisition began $20 \mathrm{~min}$ after the sample was injected and continued for $100 \mathrm{~min}$ over an $\mathrm{m} / \mathrm{z}$ range of 400 2000. For each cycle, the six most abundant ions from MS analysis were selected for MS/MS analysis, using a collision energy setting of $35 \mathrm{eV}$. A dynamic exclusion time of $60 \mathrm{~s}$ was used to discriminate against previously analyzed ions. All subcellular fractions from the $\Delta f l i C \Delta f l i B$ mutant were analyzed in addition to the PERI of the WT (Supplemental Table 2) to ensure that the loss of flagellins did not alter periplasmic proteome expression. Each sample was analyzed in triplicate.

2.8. Data Analysis. Peptides were identified by using SEQUEST to search the mass spectra from LC-MS/MS analyses. These searches were performed using the annotated S. Typhimurium 14028 FASTA file, containing 5590 protein sequences [23]. Porcine trypsin protein sequences were included in the search to detect trypsin autocleavage contaminants. The SEQUEST parameter file contained no modifications to amino acid residues and a mass error window of $3 \mathrm{~m} / \mathrm{z}$ units for precursor mass and $0 \mathrm{~m} / \mathrm{z}$ units 
for fragmentation mass. The searches allowed for all possible peptide termini, that is, not limited by tryptic terminus state. Results were filtered using the MS-Generating Function [24], a software tool that assigns $P$ values (spectral probabilities) to spectral interpretations. The prescribed spectral probability cutoff $\left(1 \mathrm{E}^{-10}\right)$ was used. This corresponded to a false-positive rate of $0.88 \%$ at the unique peptide level and $0.16 \%$ and the spectrum level using a traditional decoy approach, that is, searching against a reversed FASTA database [25].

The number of peptide observations from each protein (spectral count) was used as a measure of relative abundance. Multiple charge states of a single peptide were considered as individual observations, as were the same peptides detected in different mass spectral analyses. Similar approaches for quantitation have been described previously $[9,14,19,26]$. A protein was considered present in a sample (subcellular fraction) only if observed in at least 2 of 3 technical replicates, and means of triplicate samples were adjusted to zero if this rule was not satisfied.

Statistical analyses were performed using Microsoft Excel and R (http://www.r-project.org/). K-means clustering and construction of heat maps were done using OmniViz 6.0.

\section{Results}

3.1. Protein Identification in Salmonella Subcellular Fractions. To survey the localization of proteins in Salmonella cells as a reference of protein localization and to observe changes in protein abundance upon growth under phagosomemimicking conditions relative to standard laboratory conditions, S. Typhimurium 14028 flagellin mutant (see Section 2 for rationale) was grown in Luria-Bertani broth (LB) to log phase or in a low-phosphate, low-magnesium, low-pH minimal medium (LPM) for 4 or $20 \mathrm{~h}$. Subcellular fractionation based on osmotic shock, differential centrifugation, and differential detergent solubilization yielded CYT, IM, PERI, and OM fractions (Figure 1) from which tryptic peptides were identified using LC-MS/MS (see Section 2). The total number of peptide observations from each protein (spectral count) was used as an estimate of relative abundance, and a protein was considered present in a sample only if observed in at least two of three replicates. This step served the dual purpose of globally removing proteins with only one peptide observation and increasing confidence in peptide identifications within each subcellular fraction. The average sequence coverage for each protein was $\sim 30 \%$. Similar numbers of proteins were identified in LB (993), LPM-4h (1102), and LPM-20h (1006) growth conditions.

3.2. Subcellular Fraction Enrichment. Each subcellular fraction contained a unique protein profile (Supplemental Figure 1), although the IM contained a larger proportion of cofractionating CYT proteins, as noted previously [9]. We avoided high-pH treatment of membrane fractions [27] in an attempt to maintain physiologically relevant proteinprotein and protein-membrane interactions; thus, peripheral membrane proteins were not removed in our protocol.
STM 14028 WT and flagellin mutant

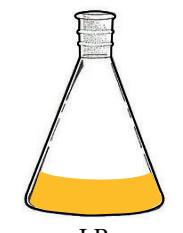

LB

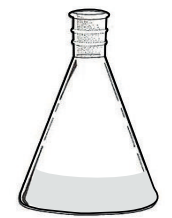

LPM $4 \mathrm{~h}$

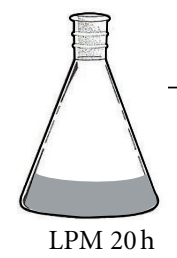

Harvest $\sim$ equal total number of cells (based on OD600)

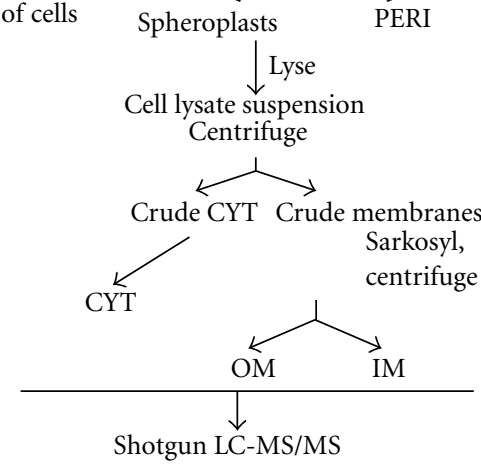

Figure 1: Experimental workflow. A fractionation scheme based on differential centrifugation and Sarkosyl solubilization of membranes was combined with spheroplasting to obtain PERI, CYT, $\mathrm{OM}$, and IM samples from S. Typhimurium strain 14028. Subcellular fractions were further processed prior to high-resolution LCMS/MS analysis.

Agreement between observed and computationally predicted protein localization was assessed. Subcellular predictions were computed using PSORTb [28], with the caveat that $\sim 17 \%$ of the observed proteins had no PSORTb subcellular assignment (unknown or unknown with multiple possible localizations). Each subcellular fractionation was enriched in the types of proteins expected to reside there (Figure 2(a); Table 1). Both the IM and OM contained a large number of predicted CYT proteins. Since many proteins were likely observed in multiple fractions as minor contaminants due to cofractionation, protein abundance contributions were more informative than the absolute number of proteins observed [9]. From this analysis, predicted CYT proteins contributed to $80-86 \%$ of the total protein abundance in CYT fractions, predicted OM proteins, to $65-80 \%$ in OM fractions, and predicted PERI proteins, to $68-75 \%$ in PERI fractions. In contrast to the expected agreement between predicted and observed enrichment, predicted IM proteins contributed to only $\sim 25 \%$ of the total protein abundance observed in IM fractions (Figure 2(b)). This relatively limited enrichment was due largely to cofractionation of abundant CYT proteins and to the general low observability of integral membrane proteins by proteomics $[29,30]$.

As many proteins involved in bacterial pathogenesis are located outside the cytoplasm where they may more readily target and respond to the host environment, we assessed our success in enriching envelope proteins in the appropriate fractions. Cell envelope (IM, PERI, and OM) proteins can be distinguished by physicochemical properties, such as hydrophobicity (IM proteins), amphipathic beta sheets (OM 


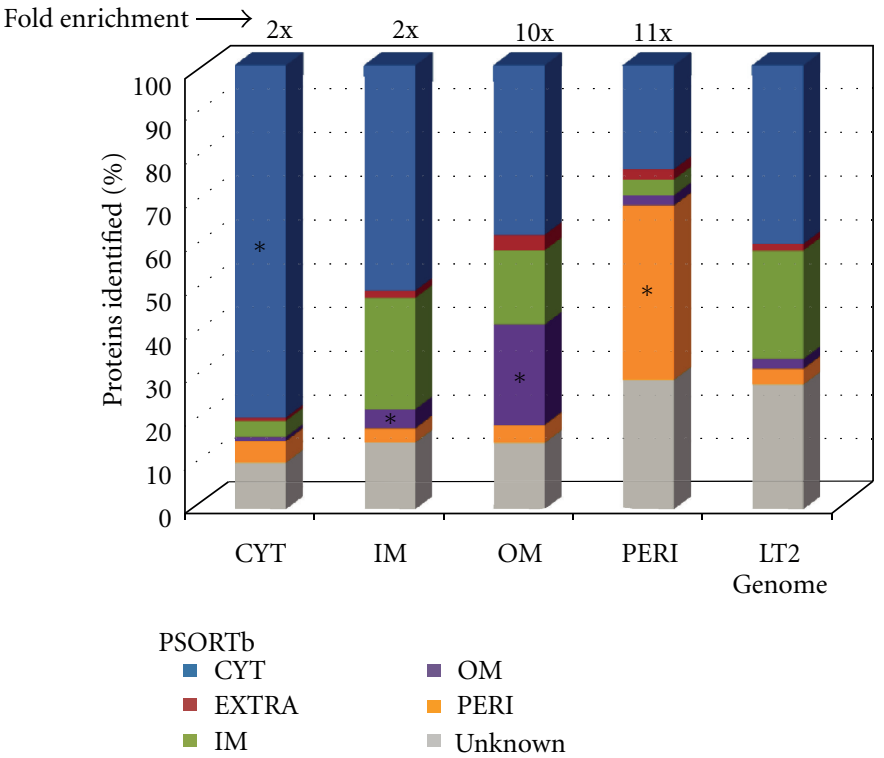

(a)

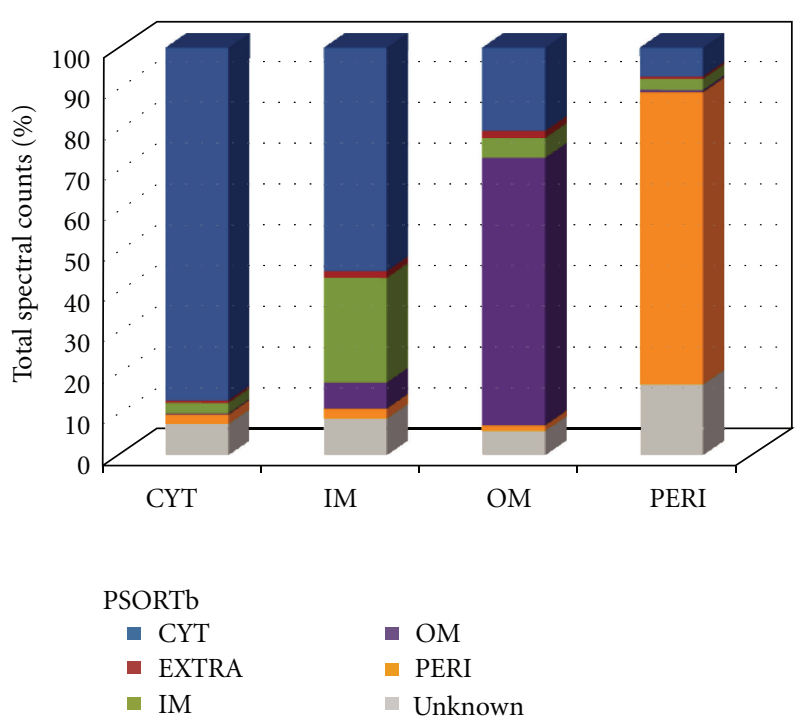

(b)

Figure 2: Distribution of proteins observed in subcellular fractions via LC-MS/MS (a). Protein composition of each subcellular fraction, based on number of proteins observed in each fraction sorted according to predicted subcellular location [16]. Data are percentage of proteins observed in each fraction. The fold-enrichment in proteins compared to the genomic potential is noted above each bar. ${ }^{*} P \leq 0.002$, $\chi^{2}$ test, compared to genome (b). Summed spectral counts (total abundance) of proteins observed in subcellular fractions.

TABLE 1: Enrichment of proteins with expected physicochemical properties.

\begin{tabular}{|c|c|c|c|c|c|c|c|}
\hline Protein type & CYT & IM & PERI & $\mathrm{OM}$ & All observed & In genome & Percentage observed \\
\hline OM beta barrel & 8 & 27 & 7 & 44 & 51 & 99 & $52 \%$ \\
\hline Signal Peps & 81 & 120 & 130 & 100 & 239 & 532 & $45 \%$ \\
\hline TMD $>0$ & 26 & 196 & 6 & 54 & 204 & 1167 & $18 \%$ \\
\hline $\mathrm{TMD}>1$ & 10 & 130 & 2 & 33 & 130 & 812 & $16 \%$ \\
\hline $\mathrm{TMD}>2$ & 4 & 97 & 2 & 21 & 97 & 683 & $14 \%$ \\
\hline $\mathrm{TMD}>3$ & 3 & 88 & 2 & 19 & 88 & 619 & $14 \%$ \\
\hline GRAVY $>0$ & 258 & 488 & 54 & 140 & 611 & 2882 & $21 \%$ \\
\hline GRAVY > 0.1 & 158 & 335 & 31 & 88 & 413 & 2201 & $19 \%$ \\
\hline GRAVY > 0.2 & 69 & 194 & 16 & 47 & 231 & 1637 & $14 \%$ \\
\hline GRAVY > 0.3 & 24 & 133 & 8 & 34 & 145 & 1276 & $11 \%$ \\
\hline GRAVY $\geq 0.5$ & 3 & 66 & 0 & 17 & 66 & 890 & $7 \%$ \\
\hline
\end{tabular}

proteins), and signal peptides (many envelope proteins). The IM, PERI, and OM were significantly enriched in envelope proteins based on observed physicochemical properties. For example, 239 proteins with predicted signal peptides (using PSORTb) were observed ( $45 \%$ of genomic potential). These proteins were mainly identified in the IM, OM, and PERI fractions, with the highest number (130) observed in the PERI (Table 1). Of 51 predicted outer membrane $\beta$-barrel proteins [31] observed (51\% of genomic potential), 44 of these were in outer membrane fractions. Similarly, proteins with predicted transmembrane $\alpha$-helices [32], a feature of integral membrane proteins, were concentrated in the IM, as expected. Of 97 proteins with $\geq 3$ transmembrane domains, all were observed in the IM, while only 24 were observed in the other three fractions combined (Table 1). Hydrophob- icity, another hallmark of integral membrane proteins [33], correlated well with proteins observed in IM samples. For the 66 proteins that could be considered very hydrophobic (hydrophobicity average $\geq 0.5$ ) [33], all were observed in the IM with high abundance values (not shown), while 3, 0, and 17 were observed in the CYT, PERI, and OM, respectively.

3.3. Determination of Primary Observed Localization. For proteins observed in multiple subcellular fractions, it was useful to identify the fraction in which each protein was observed at its highest level (i.e., the likely true subcellular location of the protein). Primary localization was determined within each growth condition by calculating the Z-score of protein abundance in each subcellular fraction. Z-scores 


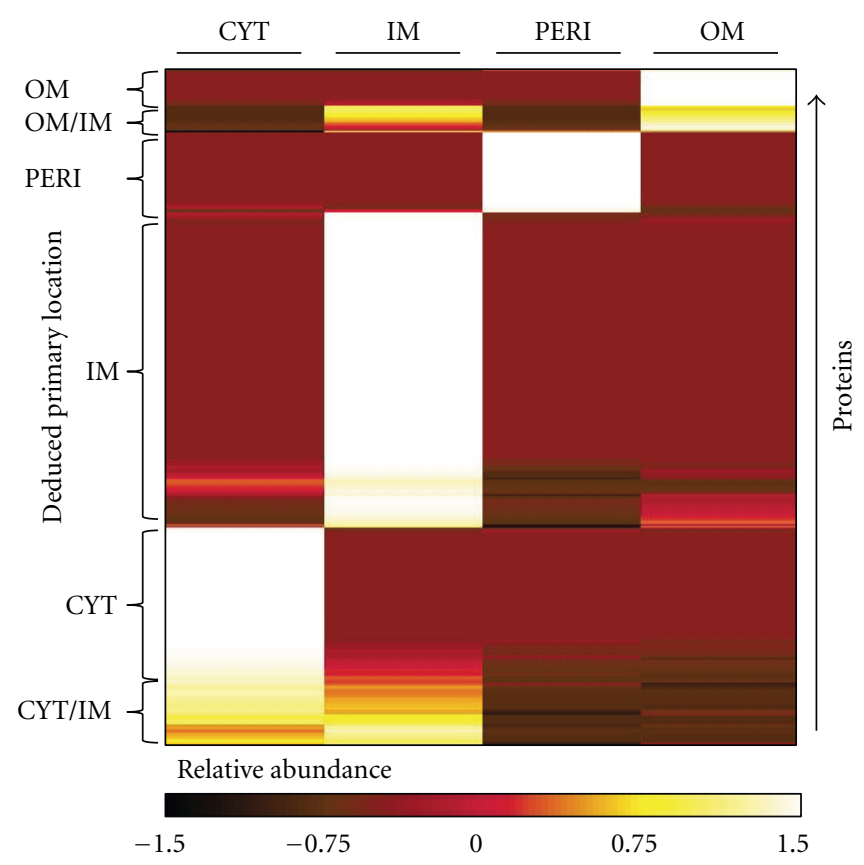

FIGURE 3: Use of Z-scores and K-means clustering to assign primary subcellular locations to proteins. Since many proteins were observed in two or more subcellular fractions, Z-scores of spectral counts across the four fractions were calculated to highlight the primary observed localization of each protein. K-means clustering was used to group proteins with similar profiles.

TABLE 2: Two-component regulators showing localization changes depending on growth conditions.

\begin{tabular}{|c|c|c|c|c|c|}
\hline Protein Description (PhoP/Q) & Gene & PSORTb v3 & $\mathrm{LB} 1^{\circ} \mathrm{Loc}$ & LPM $41^{\circ}$ Loc & LPM20 $1^{\circ} \mathrm{Loc}$ \\
\hline Sensor protein PhoQ & PhoQ & IM & $\mathrm{IM}^{*}$ & $\mathrm{IM}^{*}$ & $\mathrm{IM}^{*}$ \\
\hline DNA-binding transcriptional regulator PhoP & PhoP & Cyt & $\mathrm{IM} / \mathrm{CYT}$ & CYT & CYT \\
\hline Protein Description (ArcA/B) & Gene & PSORTb v3 & $\mathrm{LB} 1^{\circ} \mathrm{Loc}$ & LPM $41^{\circ} \mathrm{Loc}$ & LPM20 $1^{\circ} \mathrm{Loc}$ \\
\hline Aerobic respiration control sensor protein $\mathrm{ArcB}$ & $\mathrm{ArcB}$ & IM & $\mathrm{IM}^{*}$ & $\mathrm{IM}^{*}$ & $\mathrm{IM}^{*}$ \\
\hline Two-component response regulator & $\operatorname{ArcA}$ & Cyt & $\mathrm{IM}^{*}$ & IM & CYT \\
\hline
\end{tabular}

${ }^{*}$ Indicates that a protein is observed exclusively in one location.

were clustered using the K-means algorithm to group similar profiles of subcellular localization (Figure 3; Supplemental Table 3). Note that similar approaches have been described previously $[7,9]$. Using the LB culture as an example, $91 \%$ of proteins could be assigned a single primary localization using this scheme.

Some proteins $(\sim 9 \%)$ were highly observed in two or more subcellular fractions and usually occurred between the CYT and IM or IM and OM. It is noteworthy that six of the 22 IM/OM proteins were lipoproteins, which likely reflects the increased hydrophobicity and tendency to partition with the Sarkosyl-soluble IM. Other members of the IM/OM class included membrane-bound portions of type 3 secretion systems (T3SS): PrgH and PrgK of the invasion-related T3SS and FliF, FliG, and FlgE that represent the ring, basal body, and hook of the flagellar T3SS. In these cases, cofractionation reflects the association of these supramolecular structures with both membranes.

Of the proteins that were multilocalized or had secondary locations, several have been implicated in strong physiologically relevant protein-protein and protein-membrane interactions that can influence localization. For example, seven of the eight subunits of ATP synthase were observed primarily in the IM fraction (Figure 4). While only two subunits are integral to the IM, close protein-protein interactions likely mediated the cofractionation of the entire complex to the IM. Peripheral membrane proteins and multisubunit cytoplasmic proteins made up a majority of the known CYT proteins that had IM or IM/CYT as their primary observed location. Using a combination of available subunit information in Uniprot (http://www.uniprot.org/) and published literature, 45 of the $50 \mathrm{IM} / \mathrm{CYT}$ proteins were justified in their observed location due to their multimeric forms or peripheral membrane association that are tied to protein function (Supplemental Table 4).

Another group of proteins in this class were the twocomponent regulatory systems. These systems consist of a membrane-bound sensor-kinase protein and a cytoplasmic response regulator that interacts with, and is phosphorylated by, the sensor-kinase at the membrane, which promotes DNA binding and regulation of gene expression [34]. In both the PhoP/PhoQ and ArcA/ArcB systems, the sensor-kinases 


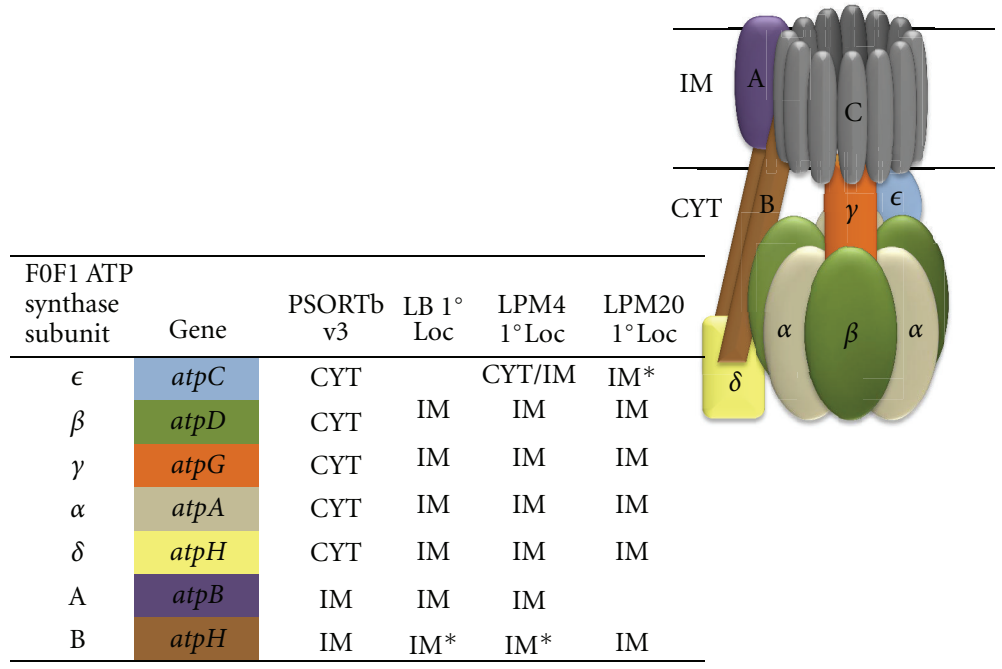

FIGURE 4: ATP synthase complex exemplifies observed protein-protein and protein-membrane interactions. Schematic representation of membrane-bound ATP synthase, modeled after KEGG Bacterial F-type ATPase Color-coded table shows protein observations in subcellular fractions. n/a: protein not observed. C: AtpE (not observed in this study). * Protein was exclusive to one subcellular fraction in a given growth condition.

were observed exclusively in the IM, while the response regulators were observed either in the IM (i.e., presumably bound to the kinase) or in the CYT (i.e., presumably interacting with DNA), depending on growth condition (Table 2). Our results iterate that PhoP is bound to DNA during growth in LPM (for either 4 or $20 \mathrm{~h}$ ), which is supported by known activation of the PhoP regulon within acidified macrophage phagosomes [35] and during growth under phagosome-mimicking conditions [26]. Conversely, the response regulator ArcA is IM-localized in cells grown in LB or those grown in LPM for a short duration, but is CYT-localized in cells grown overnight in LPM. These results provide insight into the function of this regulatory system under these specific growth conditions.

We note that some instances of multilocalized proteins may be due to the inability of our methods to perfectly resolve subcellular fractions, or may be artifacts of fractionation. As an example of the latter, DnaK and Ef-Tu can be translocated out of the cytoplasm during osmotic shock [36]. In our study, Ef-Tu was observed at high levels in both the IM and CYT. While DnaK was observed primarily in the CYT, DnaJ, a cochaperone with DnaK, was observed primarily in the IM in all growth conditions in this study.

For those proteins annotated as "putative" $(n=274)$ or "hypothetical" ( $n=92)$, we were able to confidently assign localization to a majority based on protein abundances in subcellular fractions (Supplemental Table 5). For many of these proteins, the assignment of subcellular localization as well as data on relative expression levels in different growth conditions represents the most extensive characterization available to date.

3.4. Putative Moonlighting Proteins. Some proteins were observed in unexpected subcellular locations regardless of growth condition, while the location of other proteins appeared to be influenced by growth condition. Several proteins with well-characterized housekeeping roles (e.g., enolase and glyceraldehyde-3-phosphate dehydrogenase) have been observed on the cell surfaces of pathogens, where they have secondary functions such as adhesion and immune modulation [3]. The term "moonlighting" refers to proteins that exhibit more than one biological function [1-3]. Here too, proteins that were observed in unexpected locations based on predictions, annotations, and known functions could point to novel interactions or functions yet to be characterized. In these cases, proteins with higher spectral counts (relative abundance) and greater numbers of unique peptides (more confident identifications) were considered more reliable candidates for assignment of localization.

One of the best moonlighting protein candidates observed in this study is Dps (DNA protection during starvation). This protein has been well characterized as a cytoplasmic DNA-binding protein (reviewed in [37]) and has no predicted signal peptide. In each growth condition tested, we observed Dps significantly enriched in the OM fraction (Figure 5), which shows for the first time that this protein is OM-localized in Salmonella. Dps is a known virulence determinant of Salmonella [38], but how it translocates to the OM and its role(s) at the cell surface remain to be investigated. Interestingly, Dps was recently observed on the cell surface of Escherichia coli [38, 39], where it may play a role in attachment to abiotic surfaces [38]. We observed $>2$-fold increase in the relative abundance of OMlocalized Dps between LB and LPM20 growth conditions, which indicates that Salmonella Dps is responsive to growth under phagosome-mimicking conditions (Figure 5).

Because the CYT and OM are the two most physically separated subcellular locations studied here and contain proteins with fairly distinct physicochemical properties, we considered known cytoplasmic proteins observed in the $\mathrm{OM}$ as the most promising moonlighting candidates. 


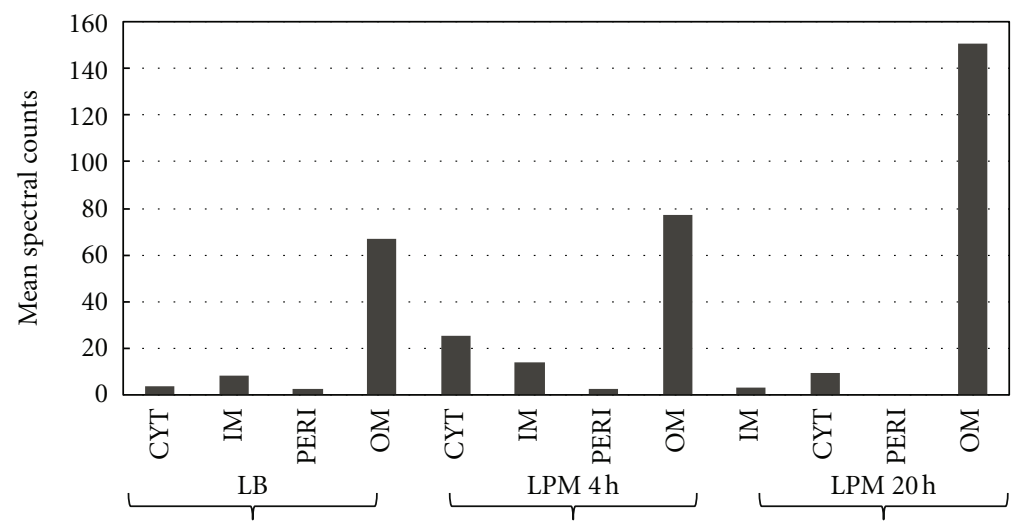

Figure 5: Localization and relative abundance of potential moonlighting protein, Dps. Spectral counts of Dps in each subcellular fraction in each growth condition. Values are means of 3 replicates.

These candidates included a (3R)-hydroxymyristoyl-ACP dehydratase (FabZ), a curved DNA-binding protein (CbpA), an imidazole glycerol-phosphate dehydratase/histidinol phosphatase (HisB), and an ATP-dependent RNA helicase (SrmB). All of these cases included proteins generally accepted to be cytoplasmic, with no detectable signal peptides, transmembrane helices, or beta barrel predictions that were confidently observed in $\mathrm{OM}$ or in a mix of $\mathrm{OM}$ and IM fractions (Supplemental Table 6). These proteins represent the first candidates for an investigation of moonlighting activities in Salmonella.

3.5. Subcellular Responses to Growth Conditions. Although not a perfect replica of the in vivo environment, defined in vitro synthetic growth media provide valuable insights into the pathogenic strategies of Salmonella $[40,41]$. Growth in LB to mid-exponential phase induces genes of the Salmonella pathogenicity island 1 (SPI-1) involved in host cell invasion [42-44], while genes of the Salmonella pathogenicity island 2 (SPI-2) can be induced by growth in LPM that simulates the environment of the Salmonella-containing vacuole (phagosome) $[45,46]$. We used these growth conditions to probe the subcellular-level responses of Salmonella to phagosomemimicking conditions.

When qualitatively assessed, similar numbers of proteins were observed in the three growth conditions: 993 in LB, 1102 in LPM-4h, and 1006 in LPM-20h. Approximately 10\% of the proteins identified in each growth condition were unique to a given culture: 175 in LB, 100 in LPM-4h, and 92 in LPM-20h (Supplemental Figure 2), and less than half of all identified proteins (688) were observed in all growth conditions, which underscores the utility of using multiple growth conditions for improved coverage of a bacterial proteome.

We have previously investigated the proteome response of Salmonella to phagosome-mimicking in vitro conditions $[19,26]$; however, the use of subcellular fractionation presented an opportunity for obtaining better proteome coverage, especially of proteins that are typically underrepresented in global proteomic strategies, in addition to highlighting the subcellular location of proteins of interest.
Based on studies of Salmonella grown in acidic minimal media $[19,26]$, we confirmed the expected increases in abundance of proteins associated with the SPI-2 T3SS (SsaC, SseA, and SsaJ), the SsrB regulon (SsrA, SsrB, and SrfN), and the PhoP regulon (PhoP, $\mathrm{PhoQ}, \mathrm{PagC}, \mathrm{MgtA}$, and MgtB) during growth in LPM (Supplemental Table 7). Conversely, proteins related to the invasion-associated SPI-1 T3SS (SipA, B, C, D, SopB, SicA, InvG, PrgK, and PrgL) decreased in abundance with growth in LPM. Further analyses focused on envelope proteins because the proteins primarily detected in previous global analyses were cytoplasmic proteins and because envelope proteins have high potential for hostpathogen interactions.

OM proteins whose abundance increased during growth in LPM included iron transporters (FepA, FhuA, IroN, and FoxA), ABC transporters, and virulence-related proteins (PagC; T3SS-related SsaC and SseC), which reflects the nutrient-limited and virulence gene-inducing nature of LPM (Figure 6(a)). A notable OM protein was the outer membrane protease PgtE that was increased 13- and 89-fold in LPM4 and LPM20, respectively $(P<0.001)$. PgtE is involved in cleavage of serum complement during the extracellular phase of Salmonella systemic infection [47], but its induction under phagosome-mimicking conditions suggests an intracellular role as well. In addition to the importance of OM proteins that increase in abundance in LPM, those that decrease in abundance may be indicative of immune evasion or virulence-related OM remodeling. For example, putative outer membrane lipoprotein maltoporin and outer membrane protein $\mathrm{N}$ were significantly decreased during growth in LPM for $20 \mathrm{~h}$ (Supplemental Table 7). Known SPI-1 T3SS-related surface proteins such as PrgK, PrgI, and InvG were also significantly decreased in the OM during growth in LPM, indicating the expected shift away from SPI-1 T3SS expression during growth in LPM.

Notable in the IM was a decrease in chemotaxis-related proteins (CheA, B, M, and Z; Tsr, Trg, and Tcp) and motility-related proteins (FliF, FliI, FliN, and MotA) in LPM compared to LB. A range of IM-integral and peripheral IM proteins of various functions were enriched during growth in LPM, including expected functions such as magnesium 


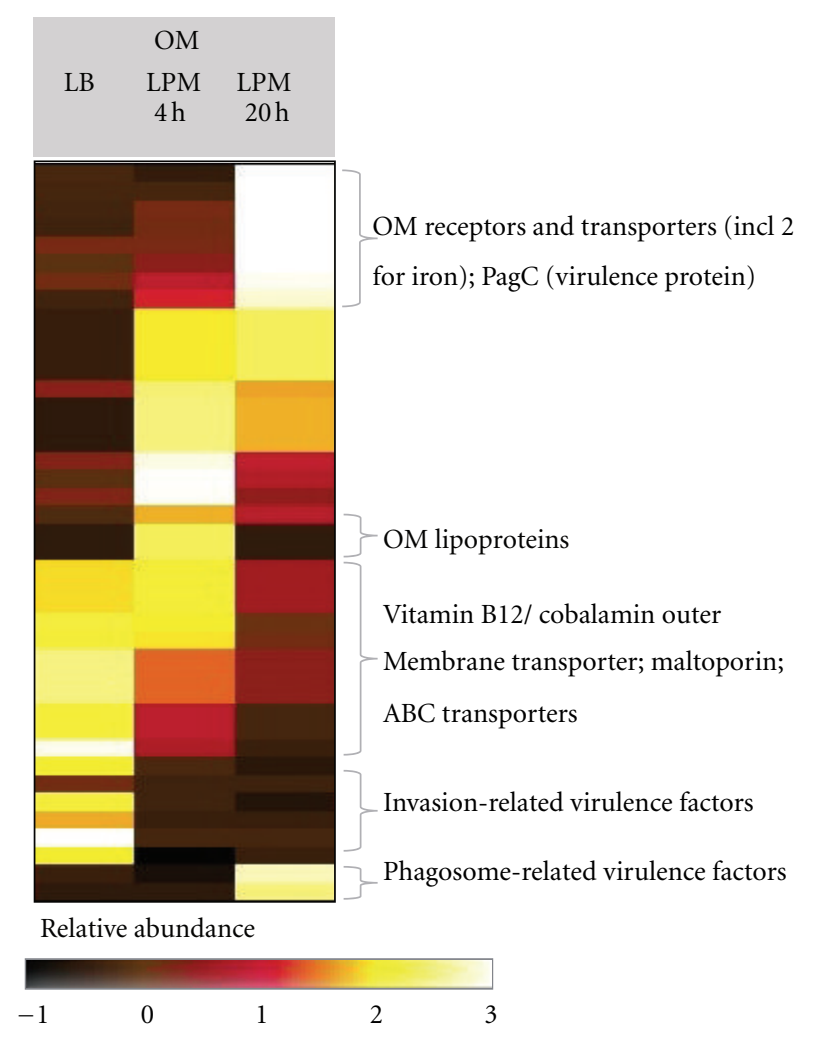

(a)

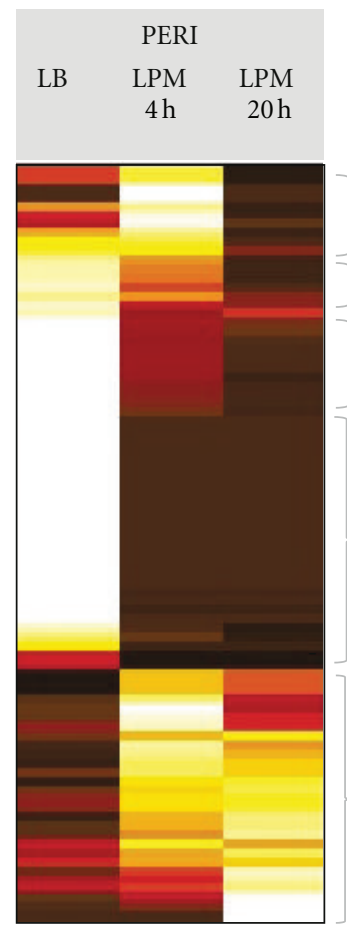

Transport proteins

Glutamine; arginine transport

Galactose; ribose; maltose; molybdate transport

Cell wall synthesis; flagella; misc

Phosphate; sulfate; thiosulfate transport Superoxide dismutases

Acid resistance

Known phagosome-related virulence factors including 2 novel recently described [9]

(b)

FIGURE 6: Heat map representation of differentially expressed OM and PERI proteins. Z-scores of protein abundance were calculated across the 3 growth conditions for proteins observed at their highest levels in the OM (a) and PERI (b) fractions. Each protein showed $\geq 2$-fold difference in abundance in any two growth conditions.

transport (MgtA and MgtB), virulence proteins (PhoQ and SsaC), and various transporters, enzymes, and proteins of unknown function (Supplemental Table 7).

The PERI shifted from transport of sugars (galactose, ribose, and maltose), oligopeptides, dipeptides, aminoacids, and related compounds (arginine and putrescine) in LB to transport of phosphate, sulfate, and thiosulfate in LPM (Figure 6(b)). Also showing increased abundance in LPM were PERI proteins involved in superoxide and acid resistance (SodC and PhoN) and known secreted factors CigR [14] and SrfN $[48,49]$ for which the subcellular location prior to being translocated into infected mammalian cells was previously unknown.

\section{Discussion}

Comparative proteomics is an emerging tool for studying bacterial pathogenesis both in vitro and during infection $[19,26,50]$. Subcellular fractionation complements such analyses by providing a means to resolve physiologically relevant protein location in the bacterium. Our analysis of CYT, IM, PERI, and OM fractions of $S$. Typhimurium grown under laboratory and phagosome-mimicking conditions yielded $\sim 1400$ unique proteins, most of which could be confidently localized to a single subcellular fraction in a given growth condition. Each subcellular fraction contained a unique protein profile (Figures 1 and 3 and Supplemental Figure 1) and protein physicochemical properties generally agreed well with their observed localization (Table 1).

To our knowledge, this study represents the most comprehensive global survey of subcellular localization in Salmonella to date. In earlier work, Coldham and Woodward [51] assessed cytosolic, cell envelope, and outer membrane protein preparations of Salmonella by extensive chromatographic fractionation followed by mass spectrometry. They observed 816 proteins, with 371 in the CYT, 565 in the envelope, and 262 in the OM samples. Of the latter 262, only 20 were OM proteins. Recently, the OM proteome of S. enterica was identified using a lipid-based method [52]. In that study, $54 \mathrm{OM}$ proteins were identified with $\geq 2$ peptides, using a multistep digest procedure on outer membrane vesicle preparations. In an early attempt to catalogue the OM proteome of Escherichia coli, Molloy and colleagues [27] identified $\sim 30$ proteins in the OM fraction, using $2 \mathrm{D}$ gel electrophoresis and MS approach. In our present study, at least $74 \mathrm{OM}$ proteins were identified in OM fractions (deduced by PSORTb prediction, annotation, or by the presence of OM $\beta$-sheets). In addition to high coverage of OM proteins, confident assignment of CYT, IM, and PERI proteins was presented (Supplemental Table 3 ). 
Among the challenges in any subcellular fractionation endeavor are to maximize fraction purity and correctly assign proteins to a subcellular location. Due to the close proximity of fractions, protein-protein interactions between fractions, or to the presence of protein domains that span multiple fractions, proteins sometimes copurify to two or more fractions. These biological phenomena are difficult to distinguish from experimental noise. In our analysis, large multi-subunit cytoplasmic complexes often concentrated in the membrane fractions (particularly the IM); likewise, many protein complexes that are known to be peripherally IM-associated also co-fractionated with the IM (e.g., ATP synthase). In cases where a protein was observed in multiple fractions, we were able to use relative abundance data to deduce the primary observed localization (Figure 3 ). However, some fractions posed more of a challenge than others; for example, the IM was more ambiguous than the OM, PERI, or CYT. Over $40 \%$ of proteins whose primary observed location was the IM were predicted by PSORTb to be cytoplasmic. It is important to note that this localization prediction does not take into account the many potential IM-interacting proteins. While the IM fraction is a good potential source of novel protein-protein and proteinmembrane interactions, a clearer picture of the integral IM landscape could emerge upon high-pH buffer treatment of the IM fraction to remove peripherally bound proteins [27].

An aspect of this study that may be helpful to others interested in subcellular proteome characterization was our use of a mutant that was depleted in an abundant cell envelope component, flagellin $(\Delta f l i C \Delta f l j B)$. Because flagellin was one of the most abundant proteins observed in the PERI (and contaminated all envelope fractions) in a preliminary subcellular proteomic analysis (Supplemental Table 1), we hypothesized that deleting flagellin genes would enable better detection of low abundance of PERI proteins and likely increase the signal of most other proteins in the PERI fraction. Flagella are not essential for survival in macrophage phagosomes [53] and are downregulated under the environmental conditions simulated by our mLPM culture condition [20]. Thus, deleting flagellins should not interfere with the physiological responses we were interested in. In addition, flagella are nonessential for growth in LB (not shown). Proteomic analysis of the wild type versus $\Delta f l i C \Delta f l j B$ mutant PERI fractions showed no differences in presence of "housekeeping" proteins such as elongation factor Tu, elongation factor G, chaperonin GroEL, and ribosomal proteins that co-fractionated with the PERI (Supplemental Table 2). Also, IM and OM proteins that co-fractionated with the PERI were observed at similar (low) levels in both the wild type and mutant. Most importantly, we observed higher spectral counts of PERI proteins in the mutant relative to wild type, and several PERI proteins were detected only in the flagellin mutant (Supplemental Table 2). Thus, we advocate the use of relevant mutations in abundant nonessential proteins for improved subcellular proteome coverage.

The availability of experimentally observed subcellular localization data for such a large number of Salmonella proteins provides opportunities for further study. Among these opportunities are using high-confidence localization information for training subcellular localization prediction tools and for computationally predicting Salmonella function in host cells through the use of genome-scale models [4]. In addition, localization data for hypothetical or uncharacterized proteins (Supplemental Table 5) is a first step towards functional characterization of these unknown proteins. To extend the utility of these data, our future study will focus on multilocalized proteins and those that changed localization depending on growth condition. Both categories present the possibility of exciting discoveries in terms of protein function. Moonlighting protein candidates are included in this class; determining the transport mechanism and secondary function of our candidates are challenges for future study.

In summary, we presented a comparative subcellular proteomic analysis of Salmonella representative of laboratory growth and infection-like states. We cataloged the confident localization of over 1000 proteins and provided evidence of differential protein movement and the appearance of some proteins in unexpected subcellular compartments. These results imply the existence of unknown transport mechanisms and novel functions for a subset of Salmonella proteins.

$\begin{array}{ll}\text { Abbreviations } \\ \text { IM: } & \text { Inner membrane } \\ \text { OM: } & \text { Outer membrane } \\ \text { CYT: } & \text { Cytoplasmic } \\ \text { PERI: } & \text { Periplasmic } \\ \text { WCL: } & \text { Whole cell lysate } \\ \text { LC-MS/MS: } & \text { Liquid chromatography-tandem mass } \\ & \text { spectrometry } \\ \text { TTSS: } & \text { Type III secretion system } \\ \text { SPI: } & \text { Salmonella pathogenicity island. }\end{array}$

\section{Acknowledgments}

The authors thank Robbie Heegel and Dr. Joseph Brown for their contributions to this research. Support for this work was provided by the National Institute of Allergy and Infectious Diseases NIH/DHHS through interagency agreement Y1-A1-8401-01. Proteomic analyses were performed in the Environmental Molecular Sciences Laboratory, a U.S Department of Energy Office of Biological and Environmental Research (DOE/BER) national scientific user facility on the Pacific Northwest National Laboratory (PNNL) campus in Richland, Washington. PNNL is a multiprogram national laboratory operated by Battelle for the DOE under Contract DE-AC05-76RL01830. This work used instrumentation and capabilities developed with funds provided by NIH grants from the National Center for Research Resources (5P41RR018522-10) and the National Institute of General Medical Sciences (8 P41 GM103493-10) and by DOE/BER. Mass spectrometry results are available via http://SysBEP.org/ and http://omics.pnl.gov/. 


\section{References}

[1] N. R. Smalheiser, "Proteins in unexpected locations," Molecular Biology of the Cell, vol. 7, no. 7, pp. 1003-1014, 1996.

[2] V. Pancholi and G. S. Chhatwal, "Housekeeping enzymes as virulence factors for pathogens," International Journal of Medical Microbiology, vol. 293, no. 6, pp. 391-401, 2003.

[3] B. Henderson and A. Martin, "Bacterial virulence in the moonlight: multitasking bacterial moonlighting proteins are virulence determinants in infectious disease," Infection and Immunity, vol. 79, no. 9, pp. 3476-3491, 2011.

[4] I. Thiele, D. R. Hyduke, B. Steeb et al., "A community effort towards a knowledge-base and mathematical model of the human pathogen Salmonella Typhimurium LT2," BMC Systems Biology, vol. 5, p. 8, 2011.

[5] M. Dreger, "Subcellular proteomics," Mass Spectrometry Reviews, vol. 22, no. 1, pp. 27-56, 2003.

[6] M. Dreger, "Proteome analysis at the level of subcellular structures," European Journal of Biochemistry, vol. 270, no. 4, pp. 589-599, 2003.

[7] S. J. Callister, M. A. Dominguez, C. D. Nicora et al., "Application of the accurate mass and time tag approach to the proteome analysis of sub-cellular fractions obtained from Rhodobacter sphaeroides 2.4.1. aerobic and photosynthetic cell cultures," Journal of Proteome Research, vol. 5, no. 8, pp. 1940-1947, 2006.

[8] M. Thein, G. Sauer, N. Paramasivam, I. Grin, and D. Linke, "Efficient subfractionation of gram-negative bacteria for proteomics studies," Journal of Proteome Research, vol. 9, no. 12, pp. 6135-6147, 2010.

[9] R. N. Brown, M. F. Romine, A. A. Schepmoes, R. D. Smith, and M. S. Lipton, "Mapping the subcellular proteome of Shewanella oneidensis MR-1 using sarkosyl-based fractionation and LC-MS/MS protein identification," Journal of Proteome Research, vol. 9, no. 9, pp. 4454-4463, 2010.

[10] E. Jung, M. Heller, J.-C. Sanchez, and D. F. Hochstrasser, "Proteomics meets cell biology: the establishment of subcellular proteomes," Electrophoresis, vol. 21, no. 16, pp. 3369-3377, 2000.

[11] C. Bell, G. T. Smith, M. J. Sweredoski, and S. Hess, "Characterization of the mycobacterium tuberculosis proteome by liquid chromatography mass spectrometry-based proteomics techniques: a comprehensive resource for tuberculosis research," Journal of Proteome Research, vol. 11, no. 1, pp. 119-130, 2012.

[12] D. Becher, K. Hempel, S. Sievers et al., "A proteomic view of an important human pathogen-towards the quantification of the entire staphylococcus aureus proteome," PLoS One, vol. 4, no. 12, p. e8176, 2009.

[13] E. Carlsohn, J. Nyström, H. Karlsson, A. M. Svennerholm, and C. L. Nilsson, "Characterization of the outer membrane protein profile from disease-related Helicobacter pylori isolates by subcellular fractionation and nano-LC FT-ICR MS analysis," Journal of Proteome Research, vol. 5, no. 11, pp. 3197-3204, 2006.

[14] G. S. Niemann, R. N. Brown, J. K. Gustin et al., "Discovery of novel secreted virulence factors from Salmonella enterica serovar Typhimurium by proteomic analysis of culture supernatants," Infection and Immunity, vol. 79, no. 1, pp. 33-43, 2011.

[15] U. Silphaduang, M. Mascarenhas, M. Karmali, and B. K. Coombes, "Repression of intracellular virulence factors in Salmonella by the Hha and YdgT nucleoid-associated proteins," Journal of Bacteriology, vol. 189, no. 9, pp. 3669-3673, 2007.
[16] D. M. Cirillo, R. H. Valdivia, D. M. Monack, and S. Falkow, "Macrophage-dependent induction of the Salmonella pathogenicity island 2 type III secretion system and its role in intracellular survival," Molecular Microbiology, vol. 30, no. 1, pp. 175-188, 1998.

[17] J. Delwick, T. Nikolaus, S. Erdogan, and M. Hensel, "Environmental regulation of Salmonella pathogenicity island 2 gene expression," Molecular Microbiology, vol. 31, no. 6, pp. 17591773, 1999.

[18] B. K. Coombes, N. F. Brown, Y. Valdez, J. H. Brumell, and B. B. Finlay, "Expression and secretion of Salmonella pathogenicity island-2 virulence genes in response to acidification exhibit differential requirements of a functional type III secretion apparatus and SsaL," Journal of Biological Chemistry, vol. 279, no. 48, pp. 49804-49815, 2004.

[19] J. N. Adkins, H. M. Mottaz, A. D. Norbeck et al., "Analysis of the Salmonella Typhimurium proteome through environmental response toward infectious conditions," Molecular and Cellular Proteomics, vol. 5, no. 8, pp. 1450-1461, 2006.

[20] L. A. Knodler, B. A. Vallance, J. Celli et al., "Dissemination of invasive Salmonella via bacterial-induced extrusion of mucosal epithelia," Proceedings of the National Academy of Sciences of the United States of America, vol. 107, no. 41, pp. 17733-17738, 2010.

[21] K. A. Datsenko and B. L. Wanner, "One-step inactivation of chromosomal genes in Escherichia coli K-12 using PCR products," Proceedings of the National Academy of Sciences of the United States of America, vol. 97, no. 12, pp. 6640-6645, 2000.

[22] Y. Shen, N. Tolić, R. Zhao et al., "High-throughput proteomics using high-efficiency multiple-capillary liquid chromatography with on-line high-performance ESI FTICR mass spectrometry," Analytical Chemistry, vol. 73, no. 13, pp. 30113021, 2001.

[23] T. Jarvik, C. Smillie, E. A. Groisman, and H. Ochman, "Shortterm signatures of evolutionary change in the Salmonella enterica serovar Typhimurium 14028 genome," Journal of Bacteriology, vol. 192, no. 2, pp. 560-567, 2010.

[24] S. Kim, N. Gupta, and P. A. Pevzner, "Spectral probabilities and generating functions of tandem mass spectra: a strike against decoy databases," Journal of Proteome Research, vol. 7, no. 8, pp. 3354-3363, 2008.

[25] J. Peng, J. E. Elias, C. C. Thoreen, L. J. Licklider, and S. P. Gygi, "Evaluation of multidimensional chromatography coupled with tandem mass spectrometry (LC/LC-MS/MS) for largescale protein analysis: the yeast proteome," Journal of Proteome Research, vol. 2, no. 1, pp. 43-50, 2003.

[26] L. Shi, C. Ansong, H. Smallwood et al., "Proteome of Salmonella enterica serotype Typhimurium grown in a low $\mathrm{Mg}^{2+} / \mathrm{pH}$ medium," Journal of Proteomics and Bioinformatics, vol. 2, no. 9, pp. 388-397, 2009.

[27] M. P. Molloy, B. R. Herbert, M. B. Slade et al., "Proteomic analysis of the Escherichia coli outer membrane," European Journal of Biochemistry, vol. 267, no. 10, pp. 2871-2881, 2000.

[28] N. Y. Yu, J. R. Wagner, M. R. Laird et al., "PSORTb 3.0: improved protein subcellular localization prediction with refined localization subcategories and predictive capabilities for all prokaryotes," Bioinformatics, vol. 26, no. 13, pp. 1608$1615,2010$.

[29] V. Santoni, M. Molloy, and T. Rabilloud, "Membrane proteins and proteomics: un amour impossible?" Electrophoresis, vol. 21, no. 6, pp. 1054-1070, 2000.

[30] T. Rabilloud, "Membrane proteins and proteomics: love is possible, but so difficult," Electrophoresis, vol. 30, supplement 
1, pp. S174-S180, 2009.

[31] F. S. Berven, K. Flikka, H. B. Jensen, and I. Eidhammer, "BOMP: a program to predict integral $\beta$-barrel outer membrane proteins encoded within genomes of Gram-negative bacteria," Nucleic Acids Research, vol. 32, pp. W394-W399, 2004.

[32] L. Käll, A. Krogh, and E. L. L. Sonnhammer, "A combined transmembrane topology and signal peptide prediction method," Journal of Molecular Biology, vol. 338, no. 5, pp. 1027-1036, 2004.

[33] J. Kyte and R. F. Doolittle, "A simple method for displaying the hydropathic character of a protein," Journal of Molecular Biology, vol. 157, no. 1, pp. 105-132, 1982.

[34] R. B. Bourret, K. A. Borkovich, and M. I. Simon, "Signal transduction pathways involving protein phosphorylation in prokaryotes," Annual Review of Biochemistry, vol. 60, pp. 401441, 1991.

[35] C. M. Alpuche Aranda, J. A. Swanson, W. P. Loomis, and S. I. Miller, "Salmonella Typhimurium activates virulence gene transcription within acidified macrophage phagosomes," Proceedings of the National Academy of Sciences of the United States of America, vol. 89, no. 21, pp. 10079-10083, 1992.

[36] C. Berrier, A. Garrigues, G. Richarme, and A. Ghazi, "Elongation factor $\mathrm{Tu}$ and DnaK are transferred from the cytoplasm to the periplasm of Escherichia coli during osmotic downshock presumably via the mechanosensitive channel MscL," Journal of Bacteriology, vol. 182, no. 1, pp. 248-251, 2000.

[37] L. N. Calhoun and Y. M. Kwon, "Structure, function and regulation of the DNA-binding protein Dps and its role in acid and oxidative stress resistance in Escherichia coli: a review," Journal of Applied Microbiology, vol. 110, no. 2, pp. 375-386, 2011.

[38] R. M. Goulter-Thorsen, I. R. Gentle, K. S. Gobius, and G. A. Dykes, "The DNA protection during starvation protein (Dps) influences attachment of Escherichia colis to abiotic surfaces," Foodborne Pathogens and Disease, vol. 8, no. 8, pp. 939-941, 2011.

[39] A. Lacqua, O. Wanner, T. Colangelo, M. G. Martinotti, and P. Landini, "Emergence of biofilm-forming subpopulations upon exposure of Escherichia coli to environmental bacteriophages," Applied and Environmental Microbiology, vol. 72, no. 1, pp. 956-959, 2006.

[40] S. Löber, D. Jäckel, N. Kaiser, and M. Hensel, "Regulation of Salmonella pathogenicity island 2 genes by independent environmental signals," International Journal of Medical Microbiology, vol. 296, no. 7, pp. 435-447, 2006.

[41] C. R. Beuzón, G. Banks, J. Deiwick, M. Hensel, and D. W. Holden, "pH-dependent secretion of SseB, a product of the SPI-2 type III secretion system of Salmonella Typhimurium," Molecular Microbiology, vol. 33, no. 4, pp. 806-816, 1999.

[42] E. A. Miao and S. I. Miller, "A conserved amino acid sequence directing intracellular type III secretion by Salmonella Typhimurium," Proceedings of the National Academy of Sciences of the United States of America, vol. 97, no. 13, pp. 7539$7544,2000$.

[43] K. Eichelberg and J. E. Galán, "Differential regulation of Salmonella Typhimurium type III secreted proteins by pathogenicity island 1 (SPI-1)-encoded transcriptional activators InvF and HilA," Infection and Immunity, vol. 67, no. 8, pp. 4099-4105, 1999.

[44] K. Ehrbar, B. Winnen, and W. D. Hardt, "The chaperone binding domain of SopE inhibits transport via flagellar and SPI-1 TTSS in the absence of InvB," Molecular Microbiology, vol. 59, no. 1, pp. 248-264, 2006.
[45] B. K. Coombes, M. J. Lowden, J. L. Bishop et al., "SseL is a Salmonella-specific translocated effector integrated into the SsrB-controlled Salmonella pathogenicity island 2 type III secretion system," Infection and Immunity, vol. 75, no. 2, pp. 574-580, 2007.

[46] X. J. Yu, K. McGourty, M. Liu, K. E. Unsworth, and D. W. Holden, "pH sensing by intracellular Salmonella induces effector translocation," Science, vol. 328, no. 5981, pp. 1040$1043,2010$.

[47] P. Ramu, R. Tanskanen, M. Holmberg, K. Lähteenmäki, T. K. Korhonen, and S. Meri, "The surface protease PgtE of Salmonella enterica affects complement activity by proteolytically cleaving C3b, C4b and C5," FEBS Letters, vol. 581, no. 9, pp. 1716-1720, 2007.

[48] S. E. Osborne, D. Walthers, A. M. Tomljenovic et al., "Pathogenic adaptation of intracellular bacteria by rewiring a cis-regulatory input function," Proceedings of the National Academy of Sciences of the United States of America, vol. 106, no. 10, pp. 3982-3987, 2009.

[49] H. Yoon, C. Ansong, J. E. McDermott et al., "Systems analysis of multiple regulator perturbations allows discovery of virulence factors in Salmonella," BMC Systems Biology, vol. 5, p. 100, 2011.

[50] L. Shi, J. N. Adkins, J. R. Coleman et al., "Proteomic analysis of Salmonella enterica serovar Typhimurium isolated from RAW 264.7 macrophages: identification of a novel protein that contributes to the replication of serovar Typhimurium inside macrophages," Journal of Biological Chemistry, vol. 281, no. 39, pp. 29131-29140, 2006.

[51] N. G. Coldham and M. J. Woodward, "Characterization of the Salmonella Typhimurium proteome by semi-automated two dimensional HPLC-mass spectrometry: detection of proteins implicated in multiple antibiotic resistance," Journal of Proteome Research, vol. 3, no. 3, pp. 595-603, 2004.

[52] D. Chooneea, R. Karlsson, V. Encheva, C. Arnold, H. Appleton, and H. Shah, "Elucidation of the outer membrane proteome of Salmonella enterica serovar Typhimurium utilising a lipid-based protein immobilization technique," BMC Microbiology, vol. 10, p. 44, 2010.

[53] C. K. Schmitt, J. S. Ikeda, S. C. Darnell et al., "Absence of all components of the flagellar export and synthesis machinery differentially alters virulence of Salmonella entericaserovar Typhimurium in models of typhoid fever, survival in macrophages, tissue culture invasiveness, and calf enterocolitis," Infection and Immunity, vol. 69, no. 9, pp. 5619-5625, 2001. 

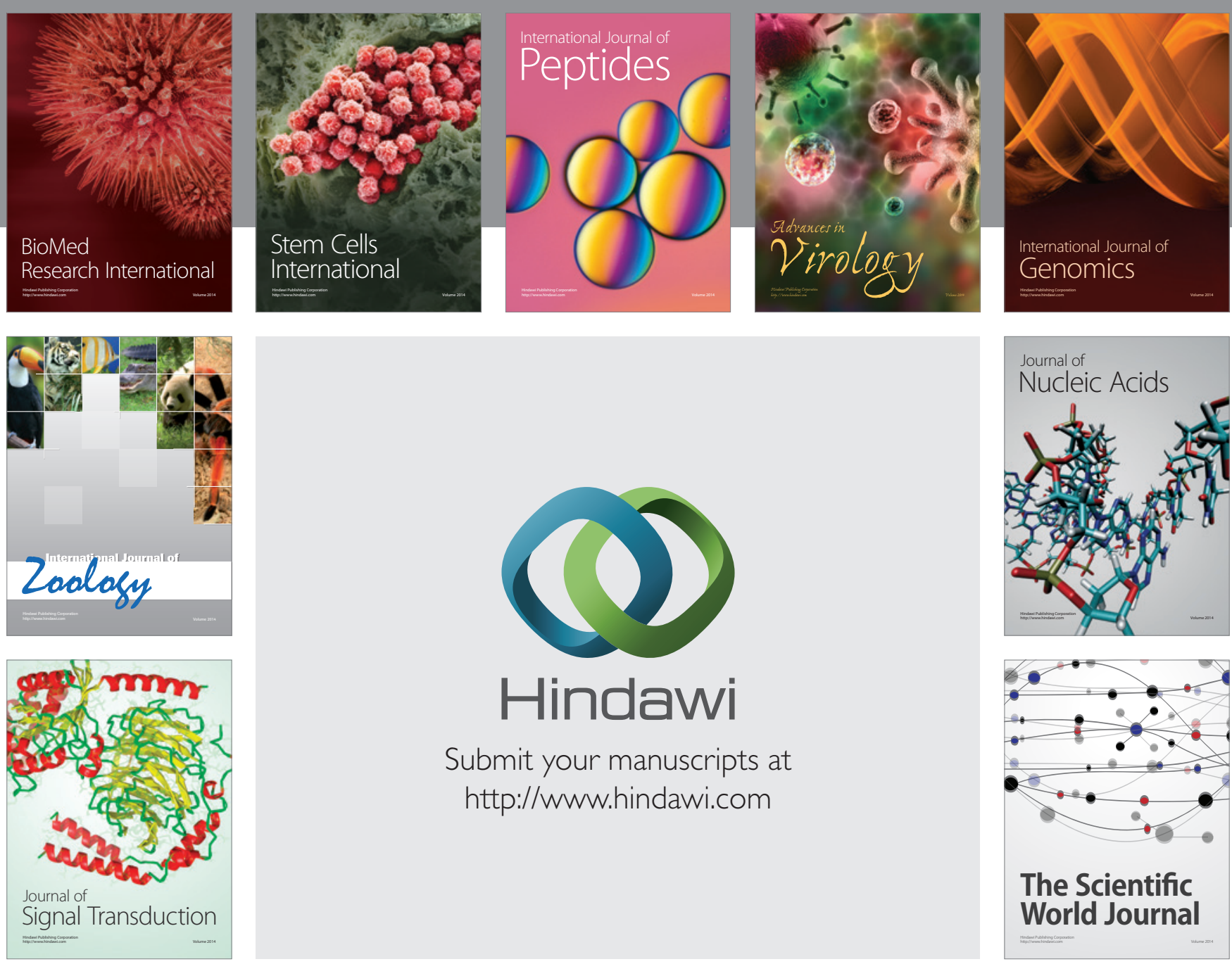

Submit your manuscripts at

http://www.hindawi.com
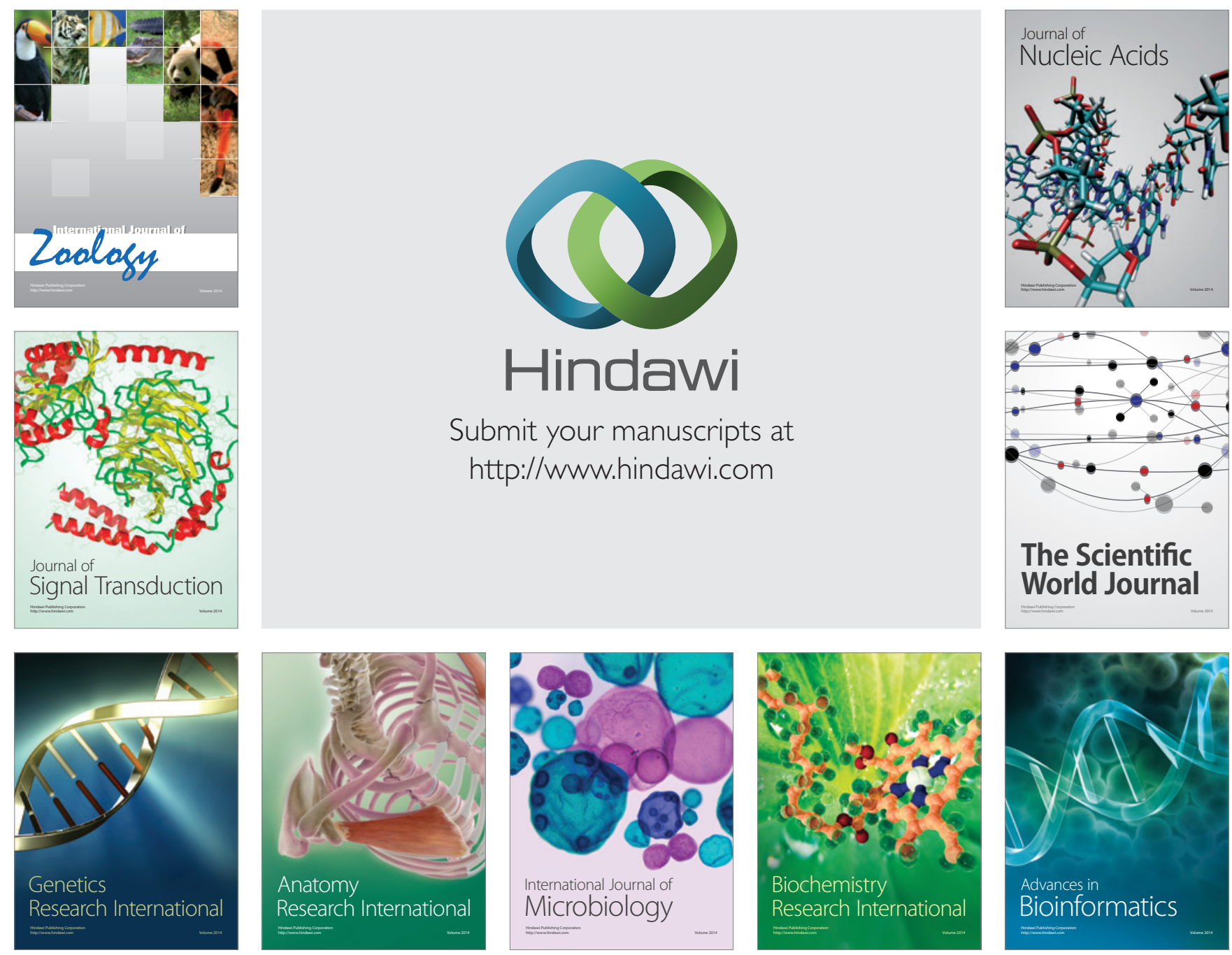

The Scientific World Journal
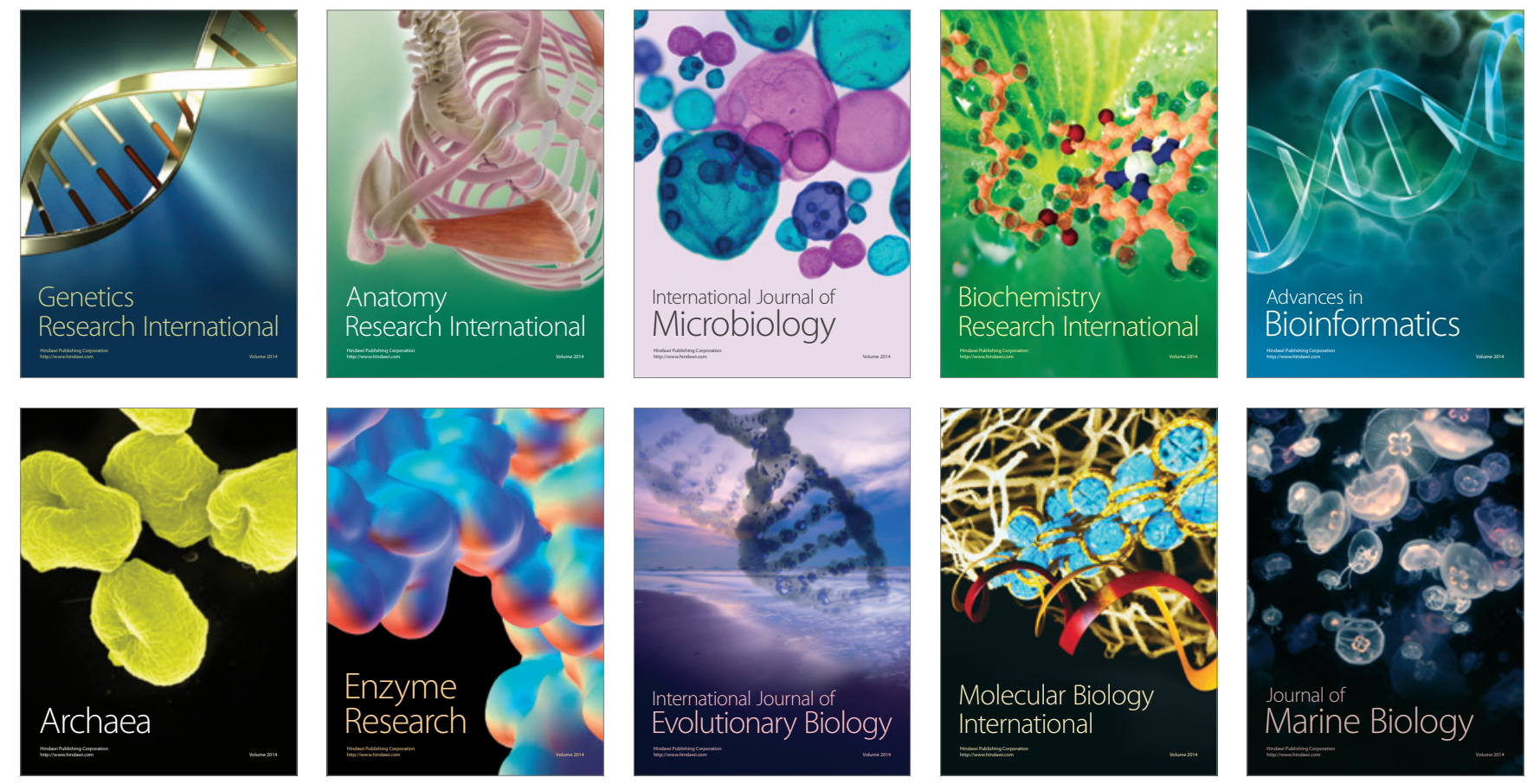